\title{
Detecting BRAF Mutations in Formalin-Fixed Melanoma: Experiences with Two State-of-the-Art Techniques
}

\author{
Nicola L. Schoenewolf ${ }^{\mathrm{a}}$ Reinhard Dummer ${ }^{\mathrm{a}}$ \\ Daniela Mihic-Probst ${ }^{b}$ Holger Moch $^{b}$ Mathew Simcock ${ }^{c}$ \\ Adrian Ochsenbein $^{d}$ Silke Gillessen $^{\text {e }}$ Peter Schraml $^{b}$ \\ Roger von Moos ${ }^{f}$ \\ on behalf of the Swiss Group for Clinical Cancer Research \\ (SAKK) \\ ${ }^{a}$ Department of Dermatology and ${ }^{b}$ Institute of Surgical Pathology, University \\ Hospital Zürich, Zürich, 'SAKK Coordinating Center, and IInselspital, Bern, \\ ${ }^{e}$ Cantonal Hospital St. Gallen, St. Gallen, and ${ }^{f}$ Kantonsspital Graubünden, \\ Chur, Switzerland
}

\section{Key Words}

BRAF mutations $\cdot \mathrm{V} 600 \mathrm{E} \cdot$ Mutation detection methods $\cdot$ Melanoma

\begin{abstract}
Background: Melanoma is characterized by a high frequency of $B R A F$ mutations. It is unknown if the BRAF mutation status has any predictive value for therapeutic approaches such as angiogenesis inhibition.
\end{abstract}

Patients and Methods: We used 2 methods to analyze the BRAF mutation status in 52 of 62 melanoma patients. Method 1 (mutation-specific real-time PCR) specifically detects the most frequent BRAF mutations, V600E and V600K. Method 2 (denaturing gel gradient electrophoresis and direct sequencing) identifies any mutations affecting exons 11 and 15 . Results: Eighteen BRAF mutations and 15 wild-type mutations were identified with both methods. One tumor had a double mutation (GAA) in codon 600. Results of 3 samples were discrepant. Additional mutations (V600M, K601E) were detected using method 2. Sixteen DNA samples were analyzable with either method 1 or method 2 . There was a significant association between BRAF V600E mutation and survival.

Conclusion: Standardized tissue fixation protocols are needed to optimize BRAF mutation analysis in melanoma. For melanoma treatment decisions, the availability of a fast and reliable BRAF V600E screening method may be sufficient. If other BRAF mutations in exons 
11 and 15 are found to be of predictive value, a combination of the 2 methods would be useful.

\section{Introduction}

$B R A F$ gene aberrations became prominent in melanoma in 2002, when Davies et al. [1] published the results of a first genome-wide analysis of melanoma tissue. This study revealed a high frequency of $B R A F$ mutations in melanoma patients occurring mainly at codon 600 . The V600E mutation occurs in $40-60 \%$ and the V600K exchange is observed in up to $20 \%$ of $B R A F$ mutations [2-4].

Currently, promising therapeutic agents such as vemurafenib (RG 7204; Roche, Basel, Switzerland) are available that specifically target the BRAF V600E mutation [511] while also exhibiting positive effects in melanoma patients with the V600K variant $[7,12]$.

Several studies have proven that $B R A F$ mutations at $\mathrm{V} 600$ lead to reduced overall survival (OS) unless treated with a $B R A F$ targeting drug $[3,13]$. Therefore, knowing the $B R A F$ mutation status in melanoma patients is clinically important. Various detection methods have been applied to detect BRAF V600 mutations [1, 3, 5, 13-21].

Here, we describe 2 different $B R A F$ mutation detection methods that were utilized in a phase II melanoma trial [13] with regard to their advantages, reliability and limitations. The impact of a $B R A F$ mutation on patient outcome was also analyzed.

\section{Patients and Methods}

Patient Selection

A total of 62 patients were treated with temozolomide and bevacizumab in this phase II trial; SAKK 50/07. All patients were considered for $B R A F$ genotyping. All patients had histologically confirmed melanoma and unresectable stage IV disease. Patient demographics have been described previously [13]. The trial was approved by the local ethics review boards as well as by Swissmedic and was registered at the National Institute of Health (www.clinicaltrial.gov; identifier number: NCT00568048). All patients gave written informed consent before any trial procedure.

Material Preparation and Selection

HE-stained sections of 62 primary melanomas that were fixed in formalin and embedded in paraffin (FFPE) were reviewed by 2 pathologists (D.M.-P., H.M.). The tumor region of interest was marked on each glass slide. DNA was extracted using the DNeasy Blood \& Tissue Kit (Qiagen, Basel, Switzerland) and tested for BRAF mutations in 2 independent laboratories.

\section{BRAF Mutation Analysis from Melanoma Tumor Tissues}

Two methods were used for the analysis of BRAF mutations. Method 1 was performed according to the method described by Benlloch et al. [14]. This mutation-specific real-time PCR enables the specific detection of the GTG to GAG transversion in codon 600 of $B R A F$, which causes an amino acid exchange from valine to glutamic acid. The sequences of the exon 15-specific primers and the MGB-TaqMan probes are shown in table 1. Depending on the genotype, distinct plots for the mutant and wild-type (WT) variants were generated. The threshold between WT and mutated genotypes was adapted to a heterozygous BRAF V600E mutated melanoma reference sequence. The reference cell culture was established from 1 melanoma patient. Final evaluation was based on allelic discrimination (fig. 1). 
In addition to $B R A F \mathrm{~V} 600 \mathrm{E}$, other less frequent $B R A F$ mutations in exons 11 and 15 have been described for melanoma [1]. Method 2 was used to find such mutations. This method is based on a denaturing gel gradient electrophoresis (DGGE) of amplified PCR products of exons 11 and 15, and direct DNA sequencing as previously described [22]. PCR products showing reduced or increased mobility shifts compared to WT BRAF were subjected to direct sequencing (fig. 2).

\section{Statistical Analysis}

Endpoints considered for the statistical analysis were disease stabilization (either complete response, partial response or stable disease) rate at 12 weeks, best overall response, and 3 time-toevent type endpoints: duration of response stabilization, progression free survival (PFS) and OS. PFS was defined as the time from trial registration until either disease progression or death, with patients censored at the time of starting second-line therapy or the last time they were known to be alive without progression.

The $B R A F$ mutation status identified by the 2 methods was used as a descriptive secondary endpoint: 3 types of $B R A F$ status groups were considered based on either $B R A F$ method 1, BRAF method 2 or combined $B R A F$ methods 1 and 2 . All endpoints were evaluated by BRAF status by means of the log-rank test for survival-type endpoints and $\chi^{2}$ or Spearman's rank correlation coefficient allowing for the ordered outcome of tumor response. No adjustment for multiple comparisons was performed. The data was analyzed in SAS (Statistical Analysis Systems, version 9.2).

\section{Results}

\section{Detection of BRAF Mutation Status by Methods 1 and 2}

DNA could be extracted from 52 of 62 (84\%) FFPE tumor samples. Due to insufficient or no tumor cells, 10 cases could not be analyzed. The BRAF mutation status was analyzable in 36 DNA samples with both methods. Eighteen BRAF V600E mutations $(50 \%)$ and 15 WT mutations (42\%) were identified with both methods. The results of 3 samples (8\%) were discrepant between the methods. Additional mutations (V600M, K601E) were obtained by using method 2. Notably, 1 of the V600E melanoma results had a GTG to GAA double point mutation. Eight DNA samples were analyzable with method 1, and 8 with method 2. No mutations were seen in $B R A F$ exon 11. The results of the $2 B R A F$ mutation analyses are shown in table 2 . Examples of mutations are shown in fig. $3 \mathrm{a}-\mathrm{e}$.

\section{BRAF Mutation Status and Tumor Response}

No statistically significant association was seen between $B R A F$ mutation status obtained by method 1, 2 or both and overall best tumor response with the use of angiogenesis inhibition in combination with an alkylating chemotherapy.

\section{BRAF Mutation Status and Time-to-Event Endpoints}

Among patients with a tumor response and a known BRAF mutation status, there was no statistically significant difference in response duration between $B R A F$ status groupings. No statistically significant difference in median PFS was observed between $B R A F$ status using $B R A F$ method 1,2 or both.

The median OS was 9.6 months (95\% CI: 8.0, 11.9). When stratified by method 1 , $B R A F$ mutation status showed a statistically significant difference $(\mathrm{p}=0.0137)$. Using method 2, BRAF mutation status was borderline statistically significant $(\mathrm{p}=0.0546)$ and when combining methods 1 and 2,BRAF mutation statuses also resulted in statistical significance $(\mathrm{p}=0.0102)$. The data are shown in table 3 . 


\section{Discussion}

\section{Advantages and Limitations of the Used Methods}

Method 1 allows the specific detection of the BRAF hotspot mutation in melanoma at codon 600. In addition to GAG (V600E) and AAG (V600K) mutations, the DNA sequencing results obtained with method 2 indicate that the TaqMan probe is obviously also able to bind a third variant, namely GAA which also codes glutamic acid. This double mutation at codon 600 is the third most frequent $B R A F$ sequence alteration and occurs in about $2 \%$ of malignant melanomas [4].

The significant advantage of method 1 lies in the TaqMan approach, which allows the rapid identification of $B R A F \mathrm{~V} 600 \mathrm{E}$ without any additional analysis such as the timeconsuming and costly DGGE and DNA sequencing. In contrast, method 2 allows the detection of any possible mutations occurring within exon 15, including other V600 variants. If any other $B R A F$ mutations besides that at codon 600 also become therapeutically relevant for melanoma patients, the TaqMan approach would not be sufficient. However, the occurrence of other mutations in melanoma, such as K601E or $\mathrm{V} 600 \mathrm{M}$, is quite low and the long-term relevance has not yet been documented.

\section{Frequency of V600 Mutations}

The frequency of the $B R A F \mathrm{~V} 600 \mathrm{E}$ mutation of $50 \%$ is comparable to that described in the literature. Recent results show that up to $20 \%$ of all $B R A F$ mutations lead to a $\mathrm{V} 600 \mathrm{~K}$ exchange, which is also targetable $[23,24]$. We were unable to find this alteration in our melanoma samples. The lack of finding V600K mutations in our patient cohort may be explained due to the relatively low number of analyzable DNA samples. However, our data are in line with the results of other studies in which much lower frequencies of the V600K mutation were found [23, 24]. Based on these data, it is also possible that the frequency of the $\mathrm{V} 600 \mathrm{~K}$ mutation is overestimated.

\section{Tumor Heterogeneity and Protocol Standardization}

An important drawback is the fact that the tumor tissue is often infiltrated and surrounded by non-tumorous cells. Depending on the level of contamination, a BRAF mutation may be overlooked, thus producing a false-negative (WT) result. We aimed to circumvent this problem by punching exclusively into areas of the tumor tissue that contained more than $80 \%$ tumor cells.

The necessity of standardized protocols for fixation, dehydration and paraffin embedding of tissues is a critical issue, particularly if the specimens to be analyzed derive from different pathology institutes. A reliable $B R A F$ mutation analysis was problematic or even impossible for about one-third of the tissue samples, suggesting more or less differing protocols used at the different pathology centers involved in this phase II trial. Standardized and optimal operating procedures are of utmost importance for reliably performing $B R A F$ mutation analysis in all tissue samples to guarantee the best benefit for melanoma patients.

\section{Outcome Data}

In our trial, statistical differences were between $B R A F \mathrm{WT}$ and mutant patients regarding OS. Whether the survival difference between $B R A F \mathrm{WT}$ and mutant patients is only due to the fact that $B R A F$ mutational status has prognostic value or if $B R A F$ 
mutational status may also be predictive for a combination treatment with bevacizumab and temozolomide cannot be concluded definitively from our data set, but should be prospectively studied. If the 2 most frequent $B R A F$ mutations, V600E and $\mathrm{V} 600 \mathrm{~K}$, are the alterations with predictive value in melanoma patients, techniques identical or similar to method 1 described in this paper may be the detection system of choice.

\section{Acknowledgements}

We thank Nikita Kobert, Marie-Therese Abdou, Martina Storz and Sonja Brun Schmid for their dedicated technical support. This work was supported by Roche Pharma (Schweiz) AG, Schering Plough and the Swiss State Secretariat for Education and Research.

\section{Disclosure Statement}

Study design, data collection, analysis and interpretation of the data, final approval of the manuscript and the decision to submit the paper for publication were the responsibility of the authors and not the sponsors. R. von Moos: Consultancy/advisory role at Roche, Bristol-Myers-Squibb and Essex AG, and speaking honoraria at Roche. R. Dummer: Had consultancy/advisory role and research funding at Astra-Zeneca and Novartis. S. Gillessen: Advisory role at Novartis. H. Moch: Currently conducting research sponsored by Roche and Novartis. All other authors: no conflict of interest to declare.

Table 1. Primer sequences and MGB-TaqMan probes for BRAF exon 15 applied in method 1

\begin{tabular}{ll}
\hline Primer & Sequence \\
\hline$B R A F$ exon 15 forward & 5'-CTACTGTTTTCCTTTACTTACTACACCTCAGA-3' \\
$B R A F$ exon 15 reverse & 5'-ATCCAGACAACTGTTCAAACTGATG-3' \\
$B R A F$ WT probe & 5'-VIC-CTAGCTACAGtGAAATC-MGB-3' \\
$B R A F$ V600E probe & 5'-FAM-TAGCTACAGaGAAATC-MGB-3' \\
\hline
\end{tabular}

BRAF WT (GtG) and mutated codon 600 (GaG) are indicated in bold lowercase letters. 
Table 2. Patient $B R A F$ characteristics: a comparison between methods 1 and 2

\begin{tabular}{|c|c|c|}
\hline \multicolumn{2}{|c|}{$B R A F$ analysis results } & \multirow{2}{*}{$\begin{array}{l}\text { Frequency, \% } \\
(n=52)\end{array}$} \\
\hline method 1 & method 2 & \\
\hline V600E & V600E* & $18(34.62)$ \\
\hline WT & WT & $15(28.85)$ \\
\hline WT & NA & 5 (9.52) \\
\hline NA & WT & $6(11.54)$ \\
\hline NA & V600E & $1(1.92)$ \\
\hline NA & V600M & $1(1.92)$ \\
\hline V600E & WT & $1(1.92)$ \\
\hline WT & V600E & $1(1.92)$ \\
\hline WT & K601E & $1(1.92)$ \\
\hline V600E & NA & $3(5.77)$ \\
\hline
\end{tabular}

$\mathrm{NA}=$ Not analyzable (no/too little DNA, no PCR product). ${ }^{*}$ One tumor with GAA mutation. Discrepant results are in bold.

Table 3. BRAF mutation status and patient outcome

\begin{tabular}{lllll}
\hline Analysis & Method & \multicolumn{2}{l}{$\begin{array}{l}\text { BRAF status [median event-free survival time, } \\
\text { months }(95 \% \mathrm{CI})]\end{array}$} & $\begin{array}{l}\text { Log-rank } \\
\text { p value }\end{array}$ \\
\cline { 3 - 4 } & & BRAF mutation & BRAF WT & \\
\hline PFS & 1 & $4.0(1.6,5.4)$ & $5.3(2.6,8.1)$ & 0.0986 \\
& 2 & $4.0(1.2,5.5)$ & $5.4(2.6,8.1)$ & 0.0571 \\
& $1+2$ & $4.0(1.7,6.6)$ & $5.5(1.3,10.9)$ & 0.0647 \\
\hline OS & 1 & $9.2(6.5,11.9)$ & $12.0(7.4,16.4)$ & 0.0137 \\
& $1+2$ & $9.6(6.6,11.9)$ & $12.6(8.4,15.6)$ & 0.0546 \\
& $9.2(6.6,11.8)$ & $12.6(7.2,16.4)$ & 0.0102 \\
\hline
\end{tabular}



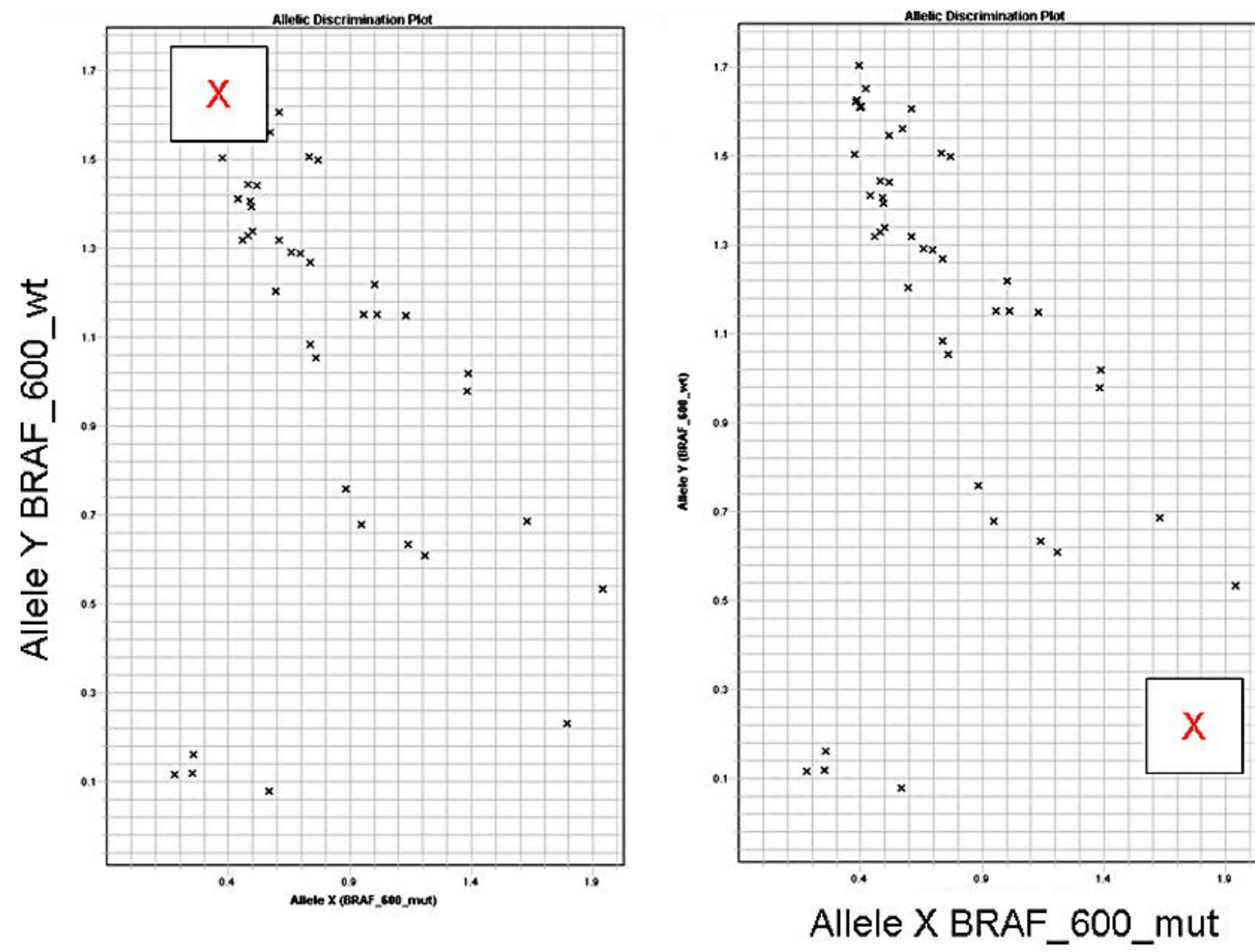

Fig. 1. Allelic discrimination plot of WT $B R A F$ (left: red x) and $B R A F$ V600E mutant (right: red x).

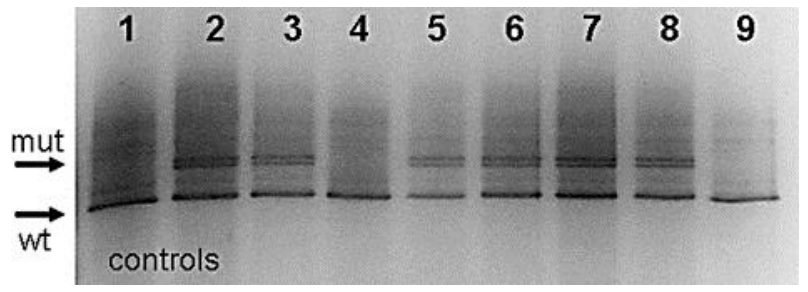

Fig. 2. DGGE of PCR products of $B R A F$ exon 15 from 7 melanomas. Lanes $1+2$ : controls for $B R A F$ WT and $B R A F \mathrm{~V} 600 \mathrm{E}$ mutation. Lanes 3-9: PCR products of 7 melanomas with $B R A F \mathrm{WT}$ (wt) and mutation (indicated by arrows). 


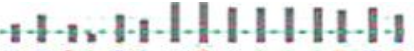

GC TACA G T GAAATC T

90

100

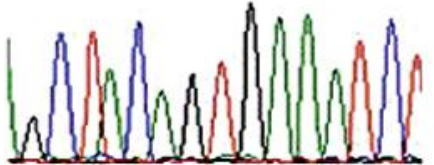

a BRAF wt V600

דo

G C TACAGAGAAATCT

$90-100$

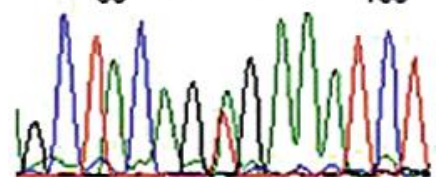

b BRAF mut/ V600E

a-1-4xta-arand

G C TACAGAAAAAT CT

90

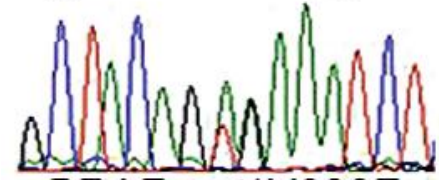

c BRAF mut V600E

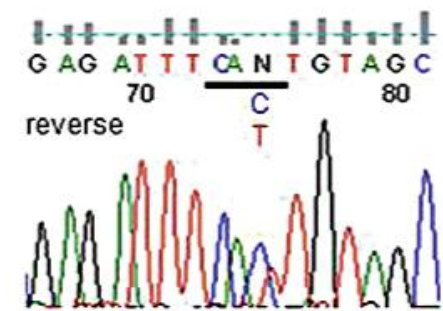

d BRAF mut V $600 \mathrm{M}$

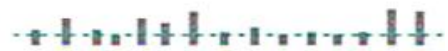

GC TACAGT GAAATCT,

90

G 100

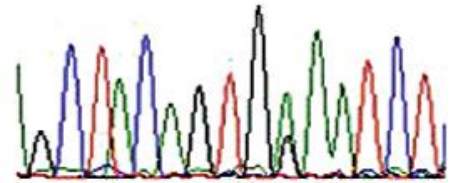

e BRAF mut/ K601E

Fig. 3. $B R A F$ exon 15 mutation status in 5 melanoma patients. a $B R A F$ WT. b, c Single and double mutations in codon 600 leading to V600E. $\mathrm{d} \mathrm{C}>\mathrm{T}$ transition (reverse sequence) leading to methionine (ATG) at codon 600. e A>G transition at codon 601. 


\section{References}

1 Davies H, Bignell GR, Cox C, Stephens P, Edkins S, Clegg S, Teague J, Woffendin H, Garnett MJ, Bottomley W, Davis N, Dicks E, Ewing R, Floyd Y, Gray K, Hall S, Hawes R, Hughes J, Kosmidou V, Menzies A, Mould C, Parker A, Stevens C, Watt S, Hooper S, Wilson R, Jayatilake H, Gusterson BA, Cooper C, Shipley J, Hargrave D, Pritchard-Jones K, Maitland N, Chenevix-Trench G, Riggins GJ, Bigner DD, Palmieri G, Cossu A, Flanagan A, Nicholson A, Ho JW, Leung SY, Yuen ST, Weber BL, Seigler HF, Darrow TL, Paterson H, Marais R, Marshall CJ, Wooster R, Stratton MR, Futreal PA: Mutations of the BRAF gene in human cancer. Nature 2002;417:949-954.

-2 Kirschner M, Helmke B, Starz H, Benner A, Thome M, Deichmann M: Preponderance of the oncogenic V599E and V599K mutations in the B-raf kinase domain is enhanced in melanoma lymph node metastases. Melanoma Res 2005;15:427-434.

-3 Long GV, Menzies AM, Nagrial AM, Haydu LE, Hamilton AL, Mann GJ, Hughes TM, Thompson JF, Scolyer RA, Kefford RF: Prognostic and clinicopathologic associations of oncogenic BRAF in metastatic melanoma. J Clin Oncol 2011;29:1239-1246.

-4 Thomas NE, Edmiston SN, Alexander A, Millikan RC, Groben PA, Hao H, Tolbert D, Berwick M, Busam K, Begg CB, Mattingly D, Ollila DW, Tse CK, Hummer A, Lee-Taylor J, Conway K: Number of nevi and earlylife ambient UV exposure are associated with BRAF-mutant melanoma. Cancer Epidemiol Biomarkers Prev 2007;16:991-997.

5 Board RE, Ellison G, Orr MC, Kemsley KR, McWalter G, Blockley LY, Dearden SP, Morris C, Ranson M Cantarini MV, Dive C, Hughes A: Detection of BRAF mutations in the tumour and serum of patients enrolled in the AZD6244 (ARRY-142886) advanced melanoma phase II study. Br J Cancer 2009;101:1724-1730.

-6 Bollag G, Hirth P, Tsai J, Zhang J, Ibrahim PN, Cho H, Spevak W, Zhang C, Zhang Y, Habets G, Burton EA, Wong B, Tsang G, West BL, Powell B, Shellooe R, Marimuthu A, Nguyen H, Zhang KY, Artis DR, Schlessinger J, Su F, Higgins B, Iyer R, D’Andrea K, Koehler A, Stumm M, Lin PS, Lee RJ, Grippo J, Puzanov I, Kim KB, Ribas A, McArthur GA, Sosman JA, Chapman PB, Flaherty KT, Xu X, Nathanson KL, Nolop K: Clinical efficacy of a RAF inhibitor needs broad target blockade in BRAF-mutant melanoma. Nature 2010;467:596-599.

7 Chapman PB, Hauschild A, Robert C, Haanen JB, Ascierto P, Larkin J, Dummer R, Garbe C, Testori A, Maio M, Hogg D, Lorigan P, Lebbe C, Jouary T, Schadendorf D, Ribas A, O'Day SJ, Sosman JA, Kirkwood JM, Eggermont AM, Dreno B, Nolop K, Li J, Nelson B, Hou J, Lee RJ, Flaherty KT, McArthur GA: Improved survival with vemurafenib in melanoma with BRAF V600E mutation. N Engl J Med 2011;364:2507-2516

8 Flaherty KT, Puzanov I, Kim KB, Ribas A, McArthur GA, Sosman JA, O’Dwyer PJ, Lee RJ, Grippo JF, Nolop $\mathrm{K}$, Chapman PB: Inhibition of mutated, activated BRAF in metastatic melanoma. N Engl J Med 2010;363:809-819.

$>9$ Lee JT, Li L, Brafford PA, van den Eijnden M, Halloran MB, Sproesser K, Haass NK, Smalley KS, Tsai J, Bollag G, Herlyn M: PLX4032, a potent inhibitor of the B-Raf V600E oncogene, selectively inhibits V600Ee-positive melanomas. Pigment Cell Melanoma Res 2010;23:820-827.

10 Vultur A, Villanueva J, Herlyn M: Targeting BRAF in advanced melanoma: a first step toward manageable disease. Clin Cancer Res 2011;17:1658-1663.

11 Yang H, Higgins B, Kolinsky K, Packman K, Go Z, Iyer R, Kolis S, Zhao S, Lee R, Grippo JF, Schostack K, Simcox ME, Heimbrook D, Bollag G, Su F: RG7204 (PLX4032), a selective BRAFV600E inhibitor, displays potent antitumor activity in preclinical melanoma models. Cancer Res 2010;70:5518-5527.

12 Rubinstein JC, Sznol M, Pavlick AC, Ariyan S, Cheng E, Bacchiocchi A, Kluger HM, Narayan D, Halaban R: Incidence of the V600K mutation among melanoma patients with BRAF mutations, and potential therapeutic response to the specific BRAF inhibitor PLX4032. J Transl Med 2010;8:67.

13 von Moos R, Seifert B, Simcock M, Goldinger SM, Gillessen S, Ochsenbein A, Michielin O, Cathomas R, Schlappi M, Moch H, Schraml PH, Mjhic-Probst D, Mamot C, Schonewolf N, Dummer R: First-line temozolomide combined with bevacizumab in metastatic melanoma: a multicentre phase II trial (SAKK 50/07). Ann Oncol 2012;23:531-536.

14 Benlloch S, Paya A, Alenda C, Bessa X, Andreu M, Jover R, Castells A, Llor X, Aranda FI, Massuti B: Detection of BRAF V600E mutation in colorectal cancer: comparison of automatic sequencing and realtime chemistry methodology. J Mol Diagn 2006;8:540-543.

15 Domingo E, Laiho P, Ollikainen M, Pinto M, Wang L, French AJ, Westra J, Frebourg T, Espin E, Armengol M, Hamelin R, Yamamoto H, Hofstra RM, Seruca R, Lindblom A, Peltomaki P, Thibodeau SN, Aaltonen LA, Schwartz S Jr: BRAF screening as a low-cost effective strategy for simplifying HNPCC genetic testing. J Med Genet 2004;41:664-668. 
16 Ellison G, Donald E, McWalter G, Knight L, Fletcher L, Sherwood J, Cantarini M, Orr M, Speake G: A comparison of arms and DNA sequencing for mutation analysis in clinical biopsy samples. J Exp Clin Cancer Res 2010;29:132.

17 Kitago M, Koyanagi K, Nakamura T, Goto Y, Faries M, O’Day SJ, Morton DL, Ferrone S, Hoon DS: mRNA expression and BRAF mutation in circulating melanoma cells isolated from peripheral blood with high molecular weight melanoma-associated antigen-specific monoclonal antibody beads. Clin Chem 2009;55:757-764.

18 Kwak JY, Kim EK, Kim JK, Han JH, Hong SW, Park TS, Choi JR: Dual priming oligonucleotide-based multiplex PCR analysis for detection of BRAFV600E mutation in FNAB samples of thyroid nodules in BRAFV600E mutation-prevalent area. Head Neck 2010;32:490-498.

19 Miller CJ, Cheung M, Sharma A, Clarke L, Helm K, Mauger D, Robertson GP: Method of mutation analysis may contribute to discrepancies in reports of (V599E)BRAF mutation frequencies in melanocytic neoplasms. J Invest Dermatol 2004;123:990-992.

20 Panka DJ, Sullivan RJ, Mier JW: An inexpensive, specific and highly sensitive protocol to detect the BrafV600E mutation in melanoma tumor biopsies and blood. Melanoma Res 2010;20:401-407.

-21 Zatelli MC, Trasforini G, Leoni S, Frigato G, Buratto M, Tagliati F, Rossi R, Cavazzini L, Roti E, degli Uberti EC: BRAF V600E mutation analysis increases diagnostic accuracy for papillary thyroid carcinoma in fineneedle aspiration biopsies. Eur J Endocrinol 2009;161:467-473.

-22 Perren A, Schmid S, Locher T, Saremaslani P, Bonvin C, Heitz PU, Komminoth P: BRAF and endocrine tumors: mutations are frequent in papillary thyroid carcinomas, rare in endocrine tumors of the gastrointestinal tract and not detected in other endocrine tumors. Endocr Relat Cancer 2004;11:855860.

23 Hay R, MacRae E, Barber D, Khalil M, Demetrick DJ: BRAF mutations in melanocytic lesions and papillary thyroid carcinoma samples identified using melting curve analysis of polymerase chain reaction products. Arch Pathol Lab Med 2007;131:1361-1367.

24 Spittle C, Ward MR, Nathanson KL, Gimotty PA, Rappaport E, Brose MS, Medina A, Letrero R, Herlyn M, Edwards RH: Application of a BRAF pyrosequencing assay for mutation detection and copy number analysis in malignant melanoma. J Mol Diagn 2007;9:464-471.

P.S. and R.v.M. shared senior authorship. 